\title{
Addendum: Sultana, J., et al. Terahertz Hollow Core Antiresonant Fiber with Metamaterial Cladding. Fibers 2020, 8, 14
}

\author{
Jakeya Sultana ${ }^{1, *}$, Md. Saiful Islam ${ }^{1,2, * \mathbb{D}}$, Cristiano M. B. Cordeiro ${ }^{2,3} \mathbb{D}^{\mathbb{D}}$, Alex Dinovitser ${ }^{1}$, Mayank Kaushik ${ }^{1}$, \\ Brian W.-H. Ng $^{1}$ (D) and Derek Abbott ${ }^{1}$ (D)
}

1 School of Electrical \& Electronic Engineering, University of Adelaide, Adelaide, SA 5005, Australia; alex.dinovitser@adelaide.edu.au (A.D.); Mayank.Kaushik@dst.defence.gov.au (M.K.); brian.ng@adelaide.edu.au (B.W.-H.N.); derek.abbott@adelaide.edu.au (D.A.)

2 Institute for Photonics \& Advanced Sensing (IPAS), University of Adelaide, Adelaide, SA 5005, Australia; cmbc@ifi.unicamp.br

3 Institute of Physics, University of Campinas, Campinas 13083-859, Brazil

* Correspondence: jakeya.sultana@adelaide.edu.au (J.S.); mdsaiful.islam@adelaide.edu.au (M.S.I.)

check for updates

Citation: Sultana, J.; Islam, M.S.;

Cordeiro, M.B.C.; Dinovitser, A.; Kaushik, M.; Ng, B.W.-H.; Abbott, D. Addendum: Sultana, J., et al.

Terahertz Hollow Core Antiresonant Fiber with Metamaterial Cladding. Fibers 2020, 8, 14. Fibers 2021, 9, 20. https://doi.org/10.3390/fib9030020

Received: 6 November 2020

Accepted: 3 February 2021

Published: 9 March 2021

Publisher's Note: MDPI stays neutral with regard to jurisdictional claims in published maps and institutional affiliations.

Copyright: (c) 2021 by the authors. Licensee MDPI, Basel, Switzerland. This article is an open access article distributed under the terms and conditions of the Creative Commons Attribution (CC BY) license (https:// creativecommons.org/licenses/by/ $4.0 /)$.
This paper [1] is an extended version of our paper published in the 44th International Conference on Infrared, Millimeter, and Terahertz Waves (IRMMW-THz), DOI: 10.1109/IRMMW-THz.2019.8873836, 2019.

\section{Reference}

1. Sultana, J.; Islam, M.S.; Cordeiro, C.M.B.; Dinovitser, A.; Kaushik, M.; Ng, B.W.H.; Abbott, D. Terahertz Hollow Core Antiresonant Fiber with Metamaterial Cladding. Fibers 2020, 8,14 . [CrossRef] 